\title{
Adaptação de instrumento para dimensionar horas diárias de assistência de enfermagem residencial*
}

\author{
ADAPTATION OF AN INSTRUMENT FOR THE MEASUREMENT OF DAILY HOURS FOR \\ NURSING CARE AT PATIENT'S HOME
}

ADAPTACION DE INSTRUMENTO PARA MEDIR HORAS DIARIAS DE
ATENCIÓN DE ENFERMERÍA DOMICILIARIA

Luiza Watanabe Dal Ben ${ }^{1}$, Regina Márcia Cardoso de Sousa ${ }^{2}$

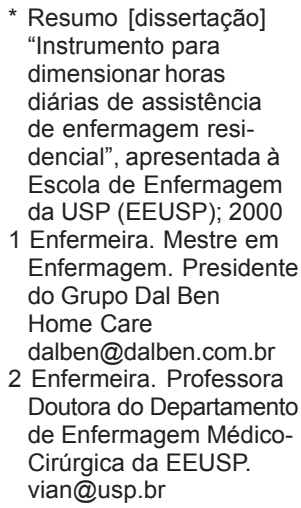

* Resumo [dissertação] "Instrumento para dimensionar horas diárias de assistência de enfermagem residencial", apresentada à Escola de Enfermagem da USP (EEUSP); 2000

1 Enfermeira. Mestre em Enfermagem. Presidente do Grupo Dal Ben Home Care dalben@dalben.com.br 2 Enfermeira. Professora Doutora do Departamento de Enfermagem MédicoCirúrgica da EEUSP. vian@usp.br

\author{
RESUMO \\ O Therapeutic Intervention \\ Scoring System Intermediate: \\ TISS-Intermediário foi \\ traduzido para a língua \\ portuguesa e adaptado para \\ estabelecer horas diárias de \\ assistência domiciliar. $O$ \\ processo de modificação do \\ instrumento, desenvolvido \\ através da Técnica Delphi, \\ teve como participantes 16 \\ enfermeiros, que atuam em \\ empresas de assistência \\ domiciliar e determinam \\ horas diárias de assistência \\ de enfermagem para \\ pacientes na residência, após \\ a hospitalização. Ao término \\ do estudo obteve-se um \\ instrumento com 104 itens, \\ para ser no futuro validado \\ clinicamente. Tal instrumento \\ ajudará enfermeiros a \\ estender cuidados de \\ enfermagem a pacientes em \\ casa, após a alta hospitalar, \\ ABSTRACT \\ The Therapeutic Intervention \\ Scoring System Intermediate: \\ TISS-Intermediate, was \\ translated into Portuguese and \\ adapted to establish the \\ number of hours daily of home \\ care. The adaptation process \\ of the instrument, developed \\ with the Delphi Technique, \\ used 16 nurses, who work in \\ home care service providers \\ and helped in calculating the \\ number of nursing care hours \\ for patients at their home after \\ a period of hospitalization. \\ At the end of the study, a 104 \\ item-instrument was obtained \\ for future clinical validation. \\ This instrument will help \\ nurses to extend nursing care \\ to patients in their homes \\ after they are discharged from \\ hospitals, especially in \\ regard to their decision- \\ making concerning patient \\ assessment.
} especialmente na tomada de decisões relativas à avaliação dos pacientes.

\section{PALAVRAS-CHAVE}

Avaliação em enfermagem. Cuidados de enfermagem. Cuidados domiciliares de saúde.

\section{KEYWORDS}

Nursing Assessment.

Nursing Care.

Home Nursing.

\section{RESUMEN}

El Therapeutic Intervention Scoring System Intermediate: TISS-Intermedio, fue traducido para el idioma portugués y adaptado para establecer las horas diarias de asistencia en el domicilio. Dieciséis enfermeros participaron del proceso de modificación del instrumento desarrollado a través de la Técnica Delphi. Esos enfermeros actúan en empresas de atención a domicilio y determinan las horas diarias de atención de enfermería a los pacientes en su domicilio después del alta. Al término del estudio se obtuvo un instrumento con 104 items para ser validado clínicamente. Tal instrumento ayudará a los enfermeros a extender sus cuidados de enfermería a pacientes que se encuentran en casa, después del alta hospitalario, especialmente en la toma de decisiones relacionadas con la evaluación de los pacientes.

\section{PALABRAS CLAVE}

Evaluación en Enfermería. Cuidados de Enfermería. Cuidados Domiciliarios de Salud. 


\section{INTRODUÇÃO}

$\mathrm{O}$ atendimento residencial tem sido uma alternativa cada dia mais evidente na assistência à saúde. A experiência mundial nos mostra que essa modalidade é uma resposta para atender a demanda de pacientes portadores de doenças crônicas, não se expondo ao risco de infecção hospitalar, evitando as reinternações e a perda do convívio familiar, além da redução dos custos. ${ }^{(1-8,10)}$.

De um modo geral a assistência domiciliária no Brasil está sendo realizada por meio de visitas domiciliárias, atendimentos domiciliários e internação domiciliária ${ }^{(3)}$. A enfermagem está sempre presente nas três modalidades, sendo o atendimento domiciliário um serviço vinculado aos grandes hospitais da rede pública, e a internação domiciliária mais presente no setor privado, tendo financiamento dos próprios pacientes e seus familiares, e reembolso de planos de saúde ${ }^{(1-3,5,9)}$.

Um dos aspectos da qualidade desse tipo de assistência é a adequação do tempo de permanência do profissional de enfermagem na residência do paciente, principalmente quando se trata de internação domiciliária. Comumente, essa adequação de tempo é determinada pelo enfermeiro ou em conjunto com o médico nas empresas que prestam assistência residencial no município de São Paulo $^{(1,9)}$. No entanto, os compradores da prestação de serviços de assistência domiciliária influenciam esse processo, procurando, com vistas aos custos, limitar as horas diárias e o número de dias que a equipe permanece na residência.

Ainda não foi definida uma resposta para se apresentar tanto à família do paciente em questão, quanto aos gestores de planos de saúde, quando o questionamento abrange a esfera da real necessidade da permanência de um profissional de enfermagem na residência, após a alta hospitalar. As justificativas são sempre colocadas em âmbito individual, porém esses questionamentos permanecem em aberto, quando se considera a necessidade de critérios determinantes para a prestação desse serviço. Procura-se, portanto, critérios abrangentes que dêem suporte em diferentes situações.

No levantamento bibliográfico dos últimos 20 anos, os estudos reconhecem muito mais o perfil do paciente que necessita da assistência de enfermagem domiciliar, do que a quantificação da demanda do cuidado no momento da alta hospitalar ${ }^{(11-12)}$.

No Brasil, o conceito de Classificação Progressiva de Paciente-CPP, como um método para instrumentalizar o dimensionamento de recursos humanos em enfermagem, foi introduzido por Ribeiro ${ }^{(13)}$ em 1972, seguido por Campedelli ${ }^{(14)}$, Fugulin $^{(15)}$ e Perroca ${ }^{(16)}$, cujos estudos estabelecem indicadores para classificar pacientes, baseados na sistemática de assistência de CPP. Afirmam ainda que a gravidade do doente da unidade tem vital importância no dimensionamento de pessoal nas instituições de saúde.

Considerando a estreita relação entre gravidade e dimensionamento de pessoal de enfermagem, encontrou-se, nos índices do estado do paciente, a possibilidade de estabelecer o número de horas diárias de enfermagem necessárias ao doente na sua casa.

Entre os índices de gravidade, o Therapeutic Intervention Scoring System (TISS) destaca-se como instrumento para dimensionar o estado de gravidade do paciente, relacionando-o com o tempo de enfermagem necessário para o seu atendimento ${ }^{(17-21)}$.

O TISS foi desenvolvido por Cullen, Civeta, Briggs, Ferrara ${ }^{(17)} \mathrm{em} 1974$ e atualizado por Cullen juntamente com Keene ${ }^{(19)}$, em 1983, e baseia-se na premissa que, independente do diagnóstico, quanto mais terapia o paciente recebe, maior é a gravidade da sua doença. $\mathrm{O}$ TISS revisado quantifica 76 intervenções terapêuticas e de monitorização, atribuindo pontos de 1 a 4 conforme a complexidade do estado do paciente, grau de invasividade e tempo despendido pela enfermagem e pelo médico, para realizar determinado procedimento.

Após a alteração para sua atualização, em 1983, o TISS foi submetido a duas modificações expressivas com a proposta de atender a diferentes finalidades. A primeira modificação foi realizada por Cullen, Nemeskal, Zaslavsky ${ }^{(18)}$, em 1994, e objetivava a mudança do índice para ser utilizado em unidades de cuidados intermediários. A segunda, por Miranda, Rijk, Schaufeli ${ }^{(21)}$, em 1996, visava simplificar a aplicação do TISS, alterando de 76 para 28 o número de itens do índice.
Adaptação de

instrumento para dimensionar horas diárias de assistência de enfermagem residencial 
Luiza Watanabe Dal Ben Regina Marcia C. de Sousa
O uso e os resultados de estudos realizados sobre a pontuação do TISS provaram ser este instrumento, um indicador confiável para dotação de pessoal de enfermagem quanto ao atendimento de pacientes em UTI. Entretanto, as características básicas dos pacientes internados nessa unidade, instáveis e recuperáveis, distanciam-se do perfil dos indivíduos indicados para atendimento residencial, inviabilizando, enfim, o uso direto do índice para a proposta do presente estudo.

Aproximando-se mais da expectativa de instrumentalizar, para quantificar a demanda de cuidados de enfermagem em pacientes de alta hospitalar para residência, encontrou-se o TISS-Intermediário. Esse instrumento, como já comentado, foi apresentado por Cullen e colaboradores ${ }^{(18)}$, em 1994, e veio atender à necessidade de avaliar e categorizar pacientes que não requerem recursos de uma UTI.

O TISS-Intermediário é composto de 85 itens, baseado nas mesmas premissas do original (para UTI), portanto sua pontuação reflete o tempo e empenho de enfermagem na assistência ao paciente, assim como o grau de gravidade da doença. Todavia apresenta algumas vantagens em relação ao original quando se considera a proposta do atual estudo: categoriza pacientes que têm doença de gravidade moderada, não adequadamente identificados pelo TISS-1983; adiciona itens e repontua, valorizando o trabalho de enfermagem, principalmente junto aos pacientes clínicos, que podem não apresentar procedimentos invasivos, mas ter uma alta demanda de cuidados de enfermagem. Caracteriza melhor os pacientes clínicos com problemas cardíacos, pulmonar e diabetes mellitus.

Acreditando-se na validade do TISS para verificar a demanda de cuidados de enfermagem à pacientes, e na maior proximidade da clientela das unidades intermediárias, daquela que necessita extensão da assistência hospitalar em sua residência, optou-se por modificar o TISSIntermediário, ajustando-o à assistência residencial.

\section{MÉTODO PARA MODIFICAÇÃO DO TISS-INTERMEDIÁRIO}

O instrumento original, TISSIntermediário, foi traduzido inicialmente para o português por um profissional bilingüe especializado na área de saúde. Para a tradução de termos técnicos foram consultados profissionais e pesquisadores na área de exames laboratoriais, farmácia, hemoterapia, controle de dor e diabetes e a publicação por Livianu, Anção, Akamine, Andrei ${ }^{(20)}$ da tradução do "Therapeutic Intervention Scoring System: update 1983". A seguir, após o instrumento estar ajustado para a língua portuguesa, foi elaborada a sua versão para a língua inglesa por um tradutor nato, especialista em linguagem médica, realizando-se assim a retrotradução (back translation) do instrumento. A comparação entre a retrotradução e a versão original publicada por Cullen, Nemeskal, Zaslavsky $^{(18)}$, foi realizada pelo Dr. Dinis Miranda, um dos autores do TISS-Simplificado para 28 itens, com domínio da língua inglesa e portuguesa e conhecimento do instrumento. $\mathrm{O}$ instrumento foi submetido a um comitê de especialistas composto por 7 avaliadores, com consolidada experiência na área hospitalar, com a finalidade de verificar a clareza e pertinência de cada um dos itens. Os avaliadores receberam o instrumento na forma original em inglês, e a tradução reelaborada para o português. Foi estabelecido um prazo de cinco dias para análise do material e solicitada atenção especial para alguns itens selecionados, cujos termos foram considerados pouco usuais no cotidiano da prática médica brasileira. Após esse período, os avaliadores foram convocados para uma reunião com o objetivo de obter um consenso sobre a versão final traduzida. Cada um dos 85 itens foi discutido exaustivamente e seu formato final determinado pelo consenso desse comitê.

O TISS-Intermediário, após ter sido submetido ao processo de tradução buscando equivalência conceitual, resultou em instrumento traduzido para o português, publicado em periódico nacional ${ }^{(22)}$.

Após essa tradução, o TISS-Intermediário foi modificado tendo como meta a construção de um novo instrumento de avaliação para determinar horas diárias de assistência de enfermagem residencial, no momento da alta hospitalar.

A sua modificação foi realizada com a aplicação da Técnica Delphi, sendo esta uma forma de abordagem que permite obter o consenso de um grupo de especialistas sobre 
uma matéria de interesse. É usada em especial quando não existe acordo sobre a matéria em estudo, ou quando há conhecimentos incompletos da natureza ou dos componentes de uma situação ${ }^{(23-24)}$.

O primeiro passo para a implementação da técnica é identificar especialistas sobre a matéria em estudo e compor um grupo de juízes para opinar sobre determinado fenômeno. A seguir, um questionário é desenvolvido, direcionado aos tópicos de interesse, depois enviado e respondido pelos juízes, retornando ao pesquisador, que, após análise e realização de uma súmula de resultados obtidos, elabora um segundo questionário, que é enviado aos juízes, acompanhado dos resultados e análise estatística do questionário anterior. Quando o segundo questionário retorna, o pesquisador repete o procedimento realizado após o primeiro, assim, sucessivamente, até que as respostas permitam atingir os objetivos propostos ${ }^{(23-24)}$.

De acordo com Spinola ${ }^{(24)}$, não existe um número ideal estabelecido de informantes, o importante é o seu grau de especialização. A avaliação do tema, os fatores de custo, natureza do problema e o número de peritos disponíveis devem ser sempre destacados.

Considerando essa afirmação, estabeleceu-se os seguintes critérios para seleção dos enfermeiros convidados a participar como juízes do presente estudo: vinculação às empresas sediadas na cidade de São Paulo, que prestam assistência na área de enfermagem residencial; participação no processo de determinação de horas diárias de assistência de enfermagem residencial, no momento da alta hospitalar; experiência profissional de pelo menos dois anos nesse modelo de assistência.

A partir da relação de 22 empresas cadastradas no Conselho Regional de Enfermagem de São Paulo, e de 12 empresas vinculadas à Associação Brasileira Home Health Care-ABRAHHCARE, foram selecionadas as empresas localizadas na cidade de São Paulo.

O contato inicial por telefone com as empresas, permitiu caracterizar as organizações da atuação na área de atendimento e ou internação domiciliária, possibilitando identificar os enfermeiros que atendiam aos critérios pré-estabelecidos para serem participantes juízes. Do total de 23 enfermeiros presentes em 8 empresas selecionadas, 17 profissionais foram selecio-nados, sendo que 1 profissional não foi incluído na pesquisa, por impossibilidade de contatá-lo dentro do tempo estabelecido para formar o grupo de juízes, 15 do sexo feminino e 1 do masculino, representando 8 empresas do setor privado. A mediana da idade foi de 34 anos; a mediana de 15 anos e meio para o tempo de conclusão do curso de enfermagem, e para experiência na área de assistência residencial foi de 5 anos e meio. Todos tinham experiência de mais de 1 ano na área hospitalar e a maioria em Unidades de Tratamento Intensivo e Gerenciamento de Serviços.

A modificação do TISS-Intermediário envolveu três fases de estudo com aplicação da técnica Delphi e para cada fase do estudo foi elaborado um instrumento específico, contendo objetivos, questões e o prazo para elaboração da resposta.

A primeira correspondência, contendo o questionário da primeira fase, também ofereceu aos juízes informações abrangentes sobre o presente estudo. As duas correspondências subseqüentes informaram resultados e tratamentos dos dados anteriormente obtidos, além de incluir o questionário da respectiva fase.

Todas as correspondências foram enviadas e recolhidas através de mensageiros no período de setembro a dezembro de 1998.

A Fase 1 da Técnica Delphi visou listar as condições ou características dos pacientes atendidos em casa, que não estavam contemplados no TISS-Intermediário e que influenciavam nas horas diárias de trabalho de enfermagem, necessárias na prática da assistência residencial. Para tanto, aos juízes do estudo foi solicitado elaborar essa listagem de acordo com sua experiência e conhecimento adquiridos nessa área. A Fase 2 tinha como objetivo verificar a pertinência das condições descritas no TISS-Intermediário acrescidas das sugestões dos juízes, na primeira fase. Considerou-se itens pertinentes aqueles que descreviam condições que estavam presentes na assistência ao paciente em sua casa, e importantes na determinação de horas diárias de assistência de enfermagem residencial.
Adaptação de

instrumento para dimensionar horas diárias de assistência de enfermagem residencial 
Luiza Watanabe Dal Ben Regina Marcia C. de Sousa
Nessa Fase, os especialistas assinalavam se a condição descrita no item era observada ou não na assistência ao paciente em sua residência, e, se esta condição subsidiava ou não a determinação de horas diárias de assistência de enfermagem. No final, do questionário, se houvesse necessidade, outras intervenções poderiam ser acrescentadas pelos juízes à listagem já apresentada. Essa última atividade complementava o objetivo da primeira fase e averiguava junto aos juízes se todas as suas sugestões, da fase anterior do estudo, haviam sido listadas.

Finalizada a Fase 2, elaborou-se a relação final das intervenções que comporiam o instrumento modificado. Nesta lista foram mantidos os itens julgados pertinentes pelos juízes. O critério estatístico adotado para manutenção das intervenções no instrumento foi a convergência de $50 \%$ ou mais das respostas, tanto no que se refere à condição do paciente observada na residência como em relação à sua importância para estabelecer horas diárias de assistência. Esse limite de corte foi determinado, após consulta com estatístico, visando ter uma margem muito maior além da recomendada na literatura. Portanto, os itens mantidos alcançaram $50 \%$ ou mais de convergência nas respostas dos dois questionamentos.

$\mathrm{Na}$ última etapa da pesquisa, coube aos juízes estimar o tempo necessário para realizar cada intervenção da listagem final, e discriminar se as intervenções eram conjugadas ou isoladas. $\mathrm{Na}$ análise das respostas, na Fase 3, manteve-se como parâmetro $50 \%$ de convergência para definição das atividades como isoladas e conjugadas. Prevaleceu a indicação de intervenção conjugada nos casos de igualdade na distribuição das respostas. Para estabelecer esse critério considerou-se a prática do atendimento residencial em que a demanda para realização de apenas uma atividade não é freqüente, devido à complexidade da condição clínica do doente ${ }^{(12)}$.

Na determinação do tempo previsto, para cada uma das intervenções, utilizou-se a moda das respostas dos juízes como medida de tendência central, seguindo-se as indicações de Berquó, Souza, Gotlieb ${ }^{(25)}$ para estabelecer seu valor.

\section{RESULTADOS E DISCUSSÃO}

Técnica Delphi - Fase 1: novas intervenções para o instrumento

Nesta Fase, 13 juízes elaboraram uma lista de condições ou características dos pacientes não contempladas no TISS-Intermediário, que influenciam a quantidade de trabalho de enfermagem na prática residencial; sendo a média de 13,3 itens propostos pelos juízes.

O conteúdo das sugestões foi analisado para reconhecer diferentes enunciados para uma mesma intervenção. Ao término dessa análise, 59 novos itens foram identificados para serem anexados ao TISS-Intermediário.

Duas intervenções foram apontadas pela maioria dos juízes: Suprir déficit de conhecimento sobre a doença ou tratamento; Orientação aos familiares (cuidadores) ou paciente para o autocuidado. As duas intervenções relacionam-se ao papel educativo do enfermeiro que auxilia a adaptação psicossocial do paciente, facilita mudança no estilo de vida, além de auxiliar a família no convívio com o doente. O suporte ao cuidador é de extrema relevância, pois, a maioria dos pacientes assistidos no domicílio são portadores de doenças crônicas, sofrendo o impacto da necessidade da mudança do estilo de vida ${ }^{(1,4,26)}$.

As características do grupo familiar devem ser analisadas com cuidado na assistência domiciliar. A efetiva participação dos familiares e a disposição dos mesmos em enfrentar a situação da doença constituem papel prioritário na recuperação do indivíduo.

A existência de um cuidador, como critério de elegibilidade de um paciente para o programa de assistência domiciliar, tem sido constante nos programas de "home care" nacional e internacional ${ }^{(26-27)}$.

\section{Técnica-Delphi - Fase 2: listagem final das intervenções}

Nesta Fase nenhum dos juízes apresentou sugestões de novos itens para listagem de intervenções e, no julgamento de pertinência, 54 novos itens foram mantidos e 5 excluídos. Em relação aos itens do TISS-Intermediário, 50 itens foram considerados pertinentes e 35 não pertinentes do TISS-Intermediário. 
Cabe observar que, analisando os itens do TISS-Intermediário, 5 foram excluídos devido ao predomínio da opinião dos juízes que não os consideraram subsídio para estabelecer horas diárias de assistência de enfermagem domiciliar. As demais 30 intervenções, que foram excluídas, pela maioria dos juízes, refletem os limites da assistência residencial para pacientes na fase aguda da doença, clinicamente instáveis, mas recuperáveis; e também, equipamentos de pouco uso na assistência à saúde na cidade de São Paulo.

Ao término desta fase do estudo foi estabelecido o conjunto de intervenções que comporia o novo instrumento, apresentado no ANEXO.

No geral, os novos itens, assinalados em negrito nesse ANEXO, acrescentam ao TISSIntermediário atividades independentes de Enfermagem, caracterizando-o como um instrumento específico para a profissão. Além disso, essa modificação propõe itens que mostram as peculiaridades da assistência de enfermagem no domicílio.

Analisando-se o "Check list" apresentado por Garrard, Bryan, Dorsey, Shapiro ${ }^{(12)}$, que mostra os problemas dos pacientes de alta para casa que referendam a necessidade de assistência de saúde na residência, observase consonância com as intervenções propostas pelos juízes do presente estudo. Dentre as intervenções citadas, direta relação pode ser feita com os problemas: necessidade de educação adicional para paciente e/ou família para prover autocuidado, após a alta, e necessidade de mudança na estrutura física da residência para cuidar do cliente.

Por outro lado, estudos recentes, que têm revisado o TISS, apontam-no como um instrumento eficiente para estabelecer carga de trabalho de enfermagem, enquanto que, descrevem como o presente estudo a necessidade de inclusão de itens relativos a procedimentos de higiene, mobilização, posicionamento do paciente, suporte afetivo, cuidados com familiares de pacientes, tarefas administrativas e gerenciais ${ }^{(28)}$.

Técnica Delphi - Fase 3: tipo de atividade e tempo utilizado na execução das intervenções

No instrumento modificado, 50 são itens mantidos do TISS-Intermediário e 54 novos itens sugeridos pelos juízes. Do total de 104 itens, 58 intervenções foram consideradas atividades isoladas e 46 conjugadas quando aplicou-se o critério estabelecido no método do presente estudo.

Das 46 atividades, consideradas conjugadas pelos juízes, 32 têm como moda de tempo estimado 1440 minutos ou 24 horas. Além disso, as respostas dos juízes foram mais coincidentes quando esse foi o tempo estimado para realizar a intervenção. Dos 14 itens restantes, 1 obteve a moda do tempo em 720 minutos ( 12 horas), 9 apresentaram entre 1 e 4 horas e 4 menos que 60 minutos.

De acordo com a literatura internacional, o conceito de assistência domiciliar envolve assistência domiciliar integrada e internação domiciliar, sendo a primeira caracterizada pela visita no domicílio da equipe interdisciplinar e a segunda pela extensão dos cuidados hospitalares, envolvendo na maioria dos casos uma assistência contínua, necessitando cobertura de 24 horas da enfermagem ${ }^{(2)}$.

Observa-se que 8 intervenções isoladas tiveram moda de tempo de execução estimada entre 1 e 3 horas. Em todas as demais atividades isoladas preponderou as indicações de menos de 60 minutos.

A somatória do tempo das atividades isoladas permite aos enfermeiros estimar horas diárias de assistência de enfermagem na residência, para um paciente de alta hospitalar, quando esse é o único tipo de atividade requerida.

Analisando as atividades conjugadas, uma lista com 32 intervenções denotam condições do paciente, que apontam diretamente 24 horas de assistência. Por outro lado, o tempo de assistência diária de um doente que apresenta as demais atividades conjugadas pode ser estabelecido pela intervenção que requer maior tempo para sua execução.

A presença de atividades isoladas e conjugadas, que demandam menos que 24 horas de assistência, requer do enfermeiro julgamento para optar por uma somatória de tempo ou manutenção de maior tempo estimado.

Em vista disso, pode-se operacionalizar o uso do instrumento final, apresentado no ANEXO do presente estudo, avaliando o paciente, registrando as condições presentes e considerando as indicações do instrumento juntamente com os apresentados no Quadro 1.
Adaptação de

instrumento para dimensionar horas diárias de assistência de enfermagem residencial 
Luiza Watanabe Dal Ben Regina Marcia C. de Sousa

Quadro 1 - Parâmetro para aplicação do novo instrumento

\begin{tabular}{|c|c|}
\hline Condição do Paciente & $\begin{array}{c}\mathrm{N}^{\circ} \text { de Horas Diárias de } \\
\text { Assistência de Enfermagem }\end{array}$ \\
\hline Atividade(s) conjugada(s) $24 \mathrm{~h}$ & $24 \mathrm{~h}$ \\
\hline Atividade(s) isolada(s) & Somatória dos tempos estimados \\
\hline Atividade(s) conjugada $(\mathrm{s})<24$ horas & $\begin{array}{l}\text { Maior tempo estimado nas atividades } \\
\text { presentes }\end{array}$ \\
\hline $\begin{array}{l}\text { Atividade(s) conjugada(s) }<24 \text { horas }+ \\
\text { atividade(s) isolada(s) }\end{array}$ & $\begin{array}{l}\text { Somatória ou maior tempo nas atividades } \\
\text { presentes }\end{array}$ \\
\hline
\end{tabular}

\section{CONCLUSÃO}

A modificação do TISS-Intermediário, para estabelecer horas diárias de enfermagem no momento da alta hospitalar, resultou em um instrumento com 104 intervenções presentes nos pacientes atendidos em suas residências no município de São Paulo, o qual apresentamos em anexo.

A dimensionalidade das intervenções de enfermagem, envolvendo a demanda em relação ao tempo entre 5 minutos e 1440 minutos (24 horas), nos permite inferir que este instrumento atende tanto a modalidade de assistência domiciliar integrada, como também a internação residencial.

Cabe ressaltar que a aplicabilidade do instrumento é restrita à determinação de tempo de permanência da equipe de enfermagem no momento da alta hospitalar. Enfatiza-se este recorte, pois, é no período da transição do hospital para a residência que as questões da esfera biológica prevalecem em relação às áreas psicossociais do paciente e da dinâmica de sua família. À medida que o paciente e a família se ajustam no enfrentamento ao novo estilo de vida, e/ou se recuperam, há a alteração da necessidade da quantidade de horas diárias de assistência de enfermagem.

Acredita-se que a modificação do TISSIntermediário, proposta neste estudo, abrange as variáveis que determinam horas diárias de assistência de enfermagem no momento da alta hospitalar, além de ser compatível com a mensuração do fenômeno que se pretende medir. Porém, sua ampla e segura utilização deve ser precedida de validação clínica que poderá reafirmar e ajustar o instrumento para uso no cotidiano da assistência domiciliar, constituindo, para o enfermeiro um dos meios do processo gerencial.

\section{CONSIDERAÇÕES FINAIS}

Esse estudo é uma pequena construção para o planejamento e sistematização da assistência domiciliária, cria um parâmetro que possibilita a sincronia necessária entre a contenção dos custos e a manutenção da qualidade do atendimento. Viabiliza um caminho efetivo para controlar os custos totais, as informações para medir resultados e satisfazer os pacientes, suas famílias e os contratantes dos prestadores de serviços.

\section{REFERÊNCIAS}

(1) Cruz LP. Assistência domiciliar: um estudo sobre a formação de profissionais e a prestação de serviços no estado de São Paulo.[dissertação]. São Paulo (SP): Fundação Getúlio Vargas; 1994.

(2)Dieckmann J. Home health administration: an overview. In: Harris MD. Handbook of home health care administration. $2^{\text {nd }}$ ed. Gaithersburg: Aspen; 1997. p.3-14.
(3) Duarte YAO, Diogo MJD. Atendimento domiciliar: um enfoque gerontológico. São Paulo: Atheneu; 2000. Atendimento domiciliário: um enfoque gerontológico; p.1-17.

(4) Fagin CM. Cost effectiveness. Nursing's value proves itself. Am J Nurs 1990; 90 (10): 16-8, $22,25$. 
(5) Farias MR. Avanço na atenção: avaliação e perspectiva para o terceiro milênio. In: Anais do $50^{\circ}$ Congresso Brasileiro de Enfermagem; 1998 set 20-25; Salvador. Salvador: ABEnSeção BA; 1998. p.139-41.

(6) National Association for Home Care. Basic statistics about home care: 1997. [on line] Disponível em: $<$ http://nahc.org/ consumer/hcstats.html $>$ (1 maio 2000).

(7) Osmo AA, Lópes Castellanos P, Makiyaura $\mathrm{MN}$, Toriake AO, Castanheira MF, De Albuquerque SMRL. Os cuidados a domicílio: da decisão política a gestão dos programas. [on line]. In:Asociación Latina para el Análisis de los Sistemas de Salud. Barcelona; 1998. Disponível em: <http://www.alass.org/ es/epistula/epistula-29-30-6.htm $>$ (15 fev 2000).

(8) World Health Organization. Home care issues at the approach of th $21^{\text {st }}$ century from a world health organization perspective: a literature review. Geneva: WHO; 1999. Annotated; pte. 1, p. 1-39.

(9) Dal Ben LW. Gestão de assistência de enfermagem residencial: experiência de uma empresa privada. In: Anais do $50^{\circ}$ Congresso Brasileiro de Enfermagem; 1998 set 20-25; Salvador. Salvador: ABEn-Seção-BA; 1998. p.171-6.

(10) Cunha ICK. Organização de serviços de assistência domiciliária de enfermagem. [dissertação]. São Paulo (SP): Escola de Enfermagem da USP; 1991.

(11) Inui TS, Stevenson KM, Plorde D, Murphy I. Needs assessment for hospital-based home care services. Res Nurs Health 1980; 3(3):101-6.

(12) Garrard J, Bryan ED, Dorsey B, Shapiro J. A checklist to assess the need for home health care: development and validation. Public Health Nurs 1987; 4(4):212-8.

(13) Ribeiro CM. Sistema de classificação de pacientes para provimento de pessoal de enfermagem.[tese] São Paulo (SP): Escola de Enfermagem da USP; 1972.

(14) Campedelli MC, Takito C, Sancinetti TR, Benko MA. Cálculo de pessoal de enfermagem: competência da enfermeira. Rev Esc Enferm USP 1987; 21(1):3-15.

(15) Fugulin FMT, Silva SHS, Shimizu HE, Campos FPF. Implantação do sistema de classificação de pacientes na unidade de clínica médica do hospital universitário da USP. Rev Med HU-USP 1994; 4 (1/2): 63-8.

(16) Perroca MG. Sistema de classificação de pacientes: construção e validação de um instrumento. [dissertação]. São Paulo (SP): Escola de Enfermagem da USP; 1996.
(17) Cullen DJ, Civeta JM, Briggs B, Ferrara LC. Therapeutic intervention scoring system: a method for quantitative comparison of patient care. Crit Care Med 1974; 2:57-60.

(18) Cullen DJ, Nemeskal AR, Zaslavsky AM. Intermediate TISS: a new therapeutic intervention scoring system for non-ICU patients. Crit Care Med 1994; 22:1406-11.

(19)Keene AR, Cullen DJ. Therapeutic intervention scoring system: update, 1983. Crit Care Med 1983; 11(11):1-3.

(20) Livianu J, Anção MS, Akamine N, Andrei AM. Índices prognósticos em UTI. In: Knobel E. Condutas no paciente grave. Rio de Janeiro: Atheneu; 1995. cap. 67, p. 823-31.

(21) Miranda DR, Rijk A, Schaufeli W. Simplified therapeutic intervention scoring system: the TISS-28 items-results from a multicenter study. Crit Care Med 1996; 24(1):64-70.

(22) Cullen DJ, Nemeskal AR, Zaslavsky AM. Sistema de pontuação de intervenções terapêuticas. Trad. de Luiza Watanabe Dal Ben, Regina Márcia Cardoso de Sousa. Nursing 2001: (40): 17-20 (edição brasileira).

(23) Faro ACM. Técnica Delphi na validação das intervenções de enfermagem. Rev Esc Enferm USP 1997; 31(2):259-73.

(24) Spinola AWP. Delfos: proposta tecnológica alternativa. São Paulo: Faculdade de Saúde Pública USP; 1984.

(25)Berquó ES, Souza JMP, Gotlieb SLD. Bioestatística. São Paulo: EPU; 1981. Análise descritiva de variáveis quantitativas: medidas de posição, de variabilidade, de assimetria e de achatamento; noções sobre correlação e regressão; p. 69-113.

(26) Duarte MJRS. Cuidadores? Por que e para quê? Atenção ao idoso no domicílio. Rev Enferm UERJ 1996; (ed extra):126-30.

(27) Ribeiro VES. O domicílio como espaço de enfermagem: a experiência da enfermagem canadense. In: Anais do $50^{\circ}$ Congresso Brasileiro de Enfermagem; 1998 set 20-25; Salvador. Salvador: ABEn-Seção-BA; 1998. p.133-38.

(28) Foundation For Research on Intensive Care in Europe. List of TISS Items in Research. [on line] Disponível em: <htttp:// www.frice.nl/TISS List_of_TISS_Items. htm> (fev.2000)
Adaptação de instrumento para dimensionar horas diárias de assistência de enfermagem residencial 
Luiza Watanabe Dal Ben

Regina Marcia C. de Sousa

ANEXO

\section{INSTRUMENTO PARADIMENSIONAR HORAS DIÁRIAS DEENFERMAGEMRESIDENCIAL}

\begin{tabular}{|c|c|}
\hline \multicolumn{2}{|r|}{ ATIVIDADES CONJUGADAS } \\
\hline $\begin{array}{l}\text { Horas de } \\
\text { Enfermagem }\end{array}$ & Condição do Paciente na Alta Hospitalar \\
\hline 24 horas & $\begin{array}{l}\text { ( ) Alimentação gastroenteral } \\
\text { ( ) Anticoagulação por via endovenosa (heparina ou dextran } 40 \text { ou dextran } 70) \\
\text { ( ) Aplicação de escala de avaliação de nível de consciência a cada } 4 \text { horas } \\
\text { ( ) Balanço hídrico a cada } 24 \text { horas } \\
\text { ( ) Balanço hídrico a cada } 6 \text { ou } 8 \text { horas } \\
\text { ( ) Digitalização iniciada nas últimas } 48 \text { horas } \\
\text { ( ) Dispositivo para incontinência urinária (uripen) } \\
\text { ( ) Drenos } \\
\text { ( ) Infusão contínua de antiarrítmicos } \\
\text { ( ) Infusão de uma (1) droga vasoativa } \\
\text { ( ) Infusão peridural } \\
\text { ( ) Intralipid ou Nutrição Parenteral Total por via periférica } \\
\text { ( ) Irrigações vesicais } \\
\text { ( ) Medidas para ajuste da família e paciente ao atendimento residencial } \\
\text { ( ) Monitorar e adequar a alimentação, hidratação, sono e repouso } \\
\text { ( ) Monitorização de diabético com níveis glicêmicos estáveis } \\
\text { ( ) Monitorização de paciente com níveis glicêmicos instáveis com prescrição médica de } \\
\text { esquema de insulina } \\
\text { ( ) Nutrição parenteral total por cateter central } \\
\text { ( ) Oxigenioterapia por máscara ou cateter nasal } \\
\text { ( ) Reposição de perda excessiva de líquidos } \\
\text { ( ) Respiração espontânea via traqueostomia com máscara ou tubo em T } \\
\text { ( ) Sedação endovenosa contínua ou Analgesia Controlada pelo Paciente (PCA) } \\
\text { ( ) Sonda nasogástrica ou sonda de gastrostomia } \\
\text { ( ) Sonda vesical de demora } \\
\text { ( ) Terapia ortopédica complicada ou cuidados com paciente acamado } \\
\text { ( ) Traqueostomia recente nas últimas } 48 \text { horas } \\
\text { ( ) Tratamento de convulsões agudas ou encefalopatia } \\
\text { ( ) Uso de dispositivos para prevenção de escaras: colchões, placas } \\
\text { ( ) Utilização de dois cateteres endovenosos } \\
\text { ( ) Utilização de um cateter endovenoso } \\
\text { ( ) Ventilação mecânica } \\
\text { ( ) Ventilação por pressão positiva contínua (CPAP) }\end{array}$ \\
\hline 12 horas & ( ) Estimular e auxiliar na deambulação \\
\hline 4 horas & ( ) Diálise peritonial crônica/ Diálise Peritonial Ambulatorial Contínua (CAPD) \\
\hline 2 horas & $\begin{array}{l}\text { ( ) Acompanhar em consultas, tratamento e exames fora da residência } \\
\text { ( ) Acompanhar e promover atividades lúdicas e ocupacionais } \\
\text { ( ) Quimioterapia endovenosa }\end{array}$ \\
\hline 1 hora & $\begin{array}{l}\text { ( ) Aminofilina ou teofilina por via endovenosa } \\
\text { ( ) Avaliação, organização e adaptação do ambiente residencial } \\
\text { ( ) Infusão de hemoderivado (albumina humana) } \\
\text { ( ) Uso de um antibiótico por via endovenosa } \\
\text { ( ) Uso de mais de um antibiótico por via endovenosa }\end{array}$ \\
\hline 30 minutos & ( ) Exposição ao sol \\
\hline 10 minutos & ( ) Aplicação de calor e frio \\
\hline 5 minutos & $\begin{array}{l}\text { ( ) Anticoagulação oral } \\
\text { ( ) Terapia ortopédica simples ou cuidados com gesso }\end{array}$ \\
\hline
\end{tabular}




\begin{tabular}{|c|c|}
\hline \multicolumn{2}{|r|}{ ATIVIDADES ISOLADAS } \\
\hline $\begin{array}{c}\text { Horas de } \\
\text { Enfermagem }\end{array}$ & Condição do Paciente na Alta Hospitalar \\
\hline 3 horas & ( ) Acompanhar a transferência do paciente do hospital para casa \\
\hline 2 horas & $\begin{array}{l}\text { ( ) Orientação aos familiares (cuidadores) ou paciente para o autocuidado } \\
\text { ( ) Processo de enfermagem: avaliação e prescrição } \\
\text { ( ) Suprir déficit de conhecimento sobre doença ou tratamento }\end{array}$ \\
\hline 1 hora & $\begin{array}{l}\text { ( ) Cuidados e orientação para pacientes portadores de ostomias } \\
\text { ( ) Drenagem de abscesso } \\
\text { ( ) Enteroclisma, enema, medicação por via retal } \\
\text { ( ) Limpeza concorrente }\end{array}$ \\
\hline 30 minutos & $\begin{array}{l}\text { ( ) Auxílio para alimentação oral } \\
\text { ( ) Banho em cadeira higiênica } \\
\text { ( ) Banho no leito } \\
\text { ( ) Cuidados com as unhas dos pés e das mãos } \\
\text { ( ) Efetuar prescrições ou orientações de outros profissionais (fono, fisio, etc.) } \\
\text { ( ) Espirometria ou exercícios respiratórios estimulados } \\
\text { ( ) Fisioterapia respiratória com duração inferior a } 5 \text { minutos } \\
\text { ( ) Passagem de intracath e outros cateteres } \\
\text { ( ) Retirada de fecaloma } \\
\text { ( ) Debridamento de feridas }\end{array}$ \\
\hline 20 minutos & $\begin{array}{l}\text { ( ) Banho assistido de chuveiro } \\
\text { ( ) Passagem de sonda vesical } \\
\text { ( ) Port-a-cath: puncão e cuidados }\end{array}$ \\
\hline 15 minutos & $\begin{array}{l}\text { ( ) Diurético endovenoso; início diurético oral ou mudança de diurético endovenoso para via oral } \\
\text { ( ) Medicação endovenosa programada de horário } \\
\text { ( ) Medicação(ões) não programada(s) por via endovenosa } \\
\text { ( ) Movimentação ativa e passiva } \\
\text { ( ) Passagem de SNE ou gástrica } \\
\text { ( ) Quimioterapia por outras vias (não EV) } \\
\text { ( ) Troca de cânula de traqueostomia } \\
\text { ( ) Uso de instrumentos ou equipamentos para a comunicação com o paciente }\end{array}$ \\
\hline 10 minutos & $\begin{array}{l}\text { ( ) Aspiração endotraqueal freqüente ( }>6 x \text { a cada } 6 \text { ou } 8 \text { horas) } \\
\text { ( ) Aspiração endotraqueal (> } 2 x \text { a cada } 6 \text { ou } 8 \text { horas) } \\
\text { ( ) Auxiliar na transferência da cama para a cadeira e vice-versa } \\
\text { ( ) Barba } \\
\text { ( ) Coleta de exames laboratoriais (exclui culturas e exames freqüentes) } \\
\text { ( ) Coleta de amostras múltiplas para análise bacteriológica para investigação de quadro infeccioso } \\
\text { (deve incluir sangue) } \\
\text { ( ) Coletas de amostras múltiplas para análise bioquímica (> } 1 \text { a cada } 6 \text { ou } 8 \text { horas) } \\
\text { ( ) Cultura de escarro, ferida ou outras } \\
\text { ( ) Cuidados com traqueostomia } \\
\text { ( ) Hidratação e lubrificação da pele } \\
\text { ( ) Lavagem de cabeça no leito } \\
\text { ( ) Massagem de conforto } \\
\text { ( ) Medidas para contenção de movimento (Quatro pontos de restrições) } \\
\text { ( ) Retirada de pontos de sutura } \\
\text { ( ) Sessão formal de fisioterapia respiratória com duração superior a } 5 \text { minutos } \\
\text { ( ) Trocas de curativos simples } \\
\text { ( ) Trocas freqüentes de curativos } \\
\text { ( ) Troca de roupa de cama }\end{array}$ \\
\hline 5 minutos & $\begin{array}{l}\text { ( ) Aplicação de medicamentos tópicos, por via oral e IM } \\
\text { ( ) Mensuração, avaliação e registro horário dos sinais vitais } \\
\text { ( ) Mensuração, avaliação e registro horário dos sinais vitais a cada } 2 \text { ou } 4 \text { horas } \\
\text { ( ) Mensuração, avaliação e registro horário dos sinais vitais a cada } 6 \text { ou } 8 \text { horas } \\
\text { ( ) Higiene íntima após as eliminações } \\
\text { ( ) Higiene ocular } \\
\text { ( ) Higiene oral } \\
\text { ( ) Mudança de decúbito } \\
\text { ( ) Pesar o paciente } \\
\text { ( ) Preparo de dieta a ser administrada por SNE/SNG } \\
\text { ( ) Troca de fraldas }\end{array}$ \\
\hline
\end{tabular}

( ) Barba

) Coleta de amostras múltiplas para análise bacteriológica para investigação de quadro infeccioso deve incluir sangue)

) Coletas de amostras múltiplas para análise bioquímica ( $>1$ a cada 6 ou 8 horas)

ida ou outra

( ) Hidratação e lubrificação da pele

( ) Lavagem de cabeça no leito

( ) Medidas para contenção de movimento (Quatro pontos de restrições)

( ) Retirada de pontos de sutura

( ) Sessão formal de fisioterapia respiratória com duração superior a 5 minutos

( ) Trocas de curativos simples

( ) Troca de roupa de cama

( ) Mensuração, avaliação e registro horário dos sinais vitais

( ) Mensuração, avaliação e registro horário dos sinais vitais a cada 2 ou 4 hora

( ) Higiene íntima após as eliminaçõe

( ) Pesar o pacient

( ) Troca de fraldas 